\title{
Investigations of prototype ejection refrigeration system driven by low grade heat
}

\author{
Dariusz Butrymowicz ${ }^{1, *}$, Jerzy Gagan ${ }^{1}$, Kamil Śmierciew ${ }^{1}$, Michał Łukaszuk ${ }^{1}$, Adam Dudar $^{1}$, Andrzej Pawluczuk ${ }^{1}$, Adam \\ Łapiński ${ }^{1}$, and Adam Kuryłowicz ${ }^{1}$ \\ ${ }^{1}$ Bialystok University of Technology, Wiejska 45C, 15351 Bialystok, Poland
}

\begin{abstract}
One of possibilities of reduction of F-gas emission is application of low grade heat to drive the refrigeration systems as well as application of natural or low warming impact working fluids. The own experimental investigation of the ejection refrigeration system operating with refrigerant $\mathrm{R}-1234 \mathrm{zeE}$ are presented and discussed. The system is driven with low grade heat source of temperature below $70^{\circ} \mathrm{C}$ and thermal capacity approximately $90 \mathrm{~kW}$. The experiments covered the effect of condensation, evaporation and generation temperatures on the capacity and thermal efficiency of the ejection refrigeration system operating for the air-conditioning purposes. Obtained results demonstrated that the proposed system may be thought as the promising heat driven refrigeration system with application of low grade motive heat sources.
\end{abstract}

\section{Introduction}

Buildings are responsible for about $30-45 \%$ of the global energy demand. The use of air conditioners and electric fans accounts for about a fifth of the total electricity in buildings around the world - or $10 \%$ of all global electricity consumption [1]. Over the next three decades, the use of ACs is set to soar, becoming one of the top drivers of global electricity demand [1]. Therefore, this sector has become an important target for reducing carbon emissions and energy consumption, because of its relevance in all these important areas [2].

Cogeneration is one of the possible way to increase the efficiency of electric energy production. While the production of electricity and heat can be conducted in an efficient manner during the heating season due to sale of the heat for the heating systems, utilization of combined production of electricity and heat decreases in summer due to the low demand for heat. This means that the solution for increasing the share of electricity produced in cogeneration is to develop effective ways of managing of the district heat during the summer. This heat is used for domestic tap water heating mainly, which involves not only the small amount of heat that is supplied to the heating system, but also the low or even very low parameters. These conditions may be thought as potentially suitable for the application of the ejection refrigeration system.

In ejection refrigeration system (Fig. 1) instead of pressurising the refrigerant by a mechanical compressor, an ejector compresses refrigerant vapour flowing from the evaporator and discharges it to the condenser. The motive vapour is generated in the vapour generator which is heated by low-temperature heat source. This paper presents development of refrigeration system equipped with vapour ejector operating with environmentally friendly new refrigerant HFO-1234zeE. Selection of this fluid was based on the comprehensive analysis of the working fluids for the ejector system with respect to Regulation of the European Parliament and the EU Council No. 517/2014 enacted on April 16th, 2014 $[3,4]$. It was shown by several researchers that ejection system can effectively operate with various natural and low warming impact synthetic refrigerants [5-8].

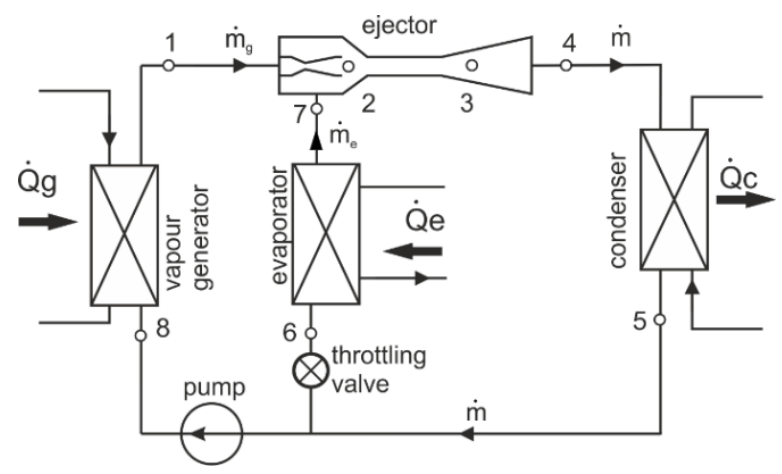

Fig. 1. Schematic of the ejector refrigeration system: $\dot{Q}_{g}$ - motive heat, $\dot{Q}_{e}$ - cooling capacity, $\dot{Q}_{c}$ - condenser capacity, $\dot{m}_{g}$ - primary (motive) mass flow rate, $\dot{m}_{e}$ secondary (sucked in by ejector) mass flow rate, $m$ - sum of $\dot{m}_{g}$ and $\dot{m}_{e}, 1,2, \ldots$ - thermodynamic state of working fluid.

Ejection refrigeration systems have been extensively investigated numerically and experimentally in recent years. The most comprehensive state-of-the-art study recent on ejection technology was presented by Chen et al. [9]. Besagni et al. [10] presented review on ejection refrigeration. These reviews gave all detail information

Corresponding author: d.butrymowicz@pb.edu.pl 
on ejector working principles, selection of the working fluids and ejection refrigeration technology as well. Elbel and Lawrence [11] presented review focused on ejectors applied for work recovery.

Butrymowicz et al. [12] presented the first experimental results of the ejector refrigeration system operating with isobutane driven by low grade heat source. Results presented in [12] showed that it is possible to use the ejection refrigeration system driven by heat gained from the district heat distribution network. During summer season the temperature of hot water is below $70^{\circ} \mathrm{C}$, and sometimes even below $65^{\circ} \mathrm{C}$. This means that application of the ejection refrigeration system may be thought as an effective solution for the production of chilled water for the air-conditioning with cooperation of the district heating system. The motive heat for the ejection system can be gained directly from the district heating system. This is much more attractive way for production of chilled water in terms of application because it allows for utilisation of low temperature heat during summer season for the air conditioning purposes.

In this paper the own investigation of the ejection refrigeration system operating with HFO group refrigerant R-1234zeE have been presented and discussed. It was shown by the authors in [13] that the ejection air-conditioning system driven by solar heat can effectively operate with low warming impact refrigerant R-600a (isobutane). However, isobutane is classified as explosive, therefore it might be considered as dangerous in large commercial refrigeration and air-conditioning. Here, ejection-based refrigeration system with safe R$1234 z e E$ driven by low temperature heat source of app. $90 \mathrm{~kW}$ capacity is presented.

\section{Methodology and apparatus}

Experiments covered various operation parameters. For all of the runs the generator and the evaporator temperatures were kept constant, and condensation temperature was a variable parameter. The average operation parameters with deviations for the system are listed in Table 1, and separately for the ejector in Table 2.

The experimental rig presented in Fig. 2 was build and instrumented for operation with R1234zeE. The main elements of the rig are listed in the figure caption. The geometry of the test ejector is presented in Fig. 3. The testing stand was equipped with the temperature sensors and pressure transducers marked in Fig. 3 as (RTD) and (P), respectively, installed at the critical locations and other locations of interest. Pressure transducers of accuracy $0.25 \%$ of the full range were used during the experiments. The pressure transducer of 0-2.5 MPa scale was used to measure the motive stream parameters and 0-1 MPa were used at the other locations. The RTD temperature sensors (Pt100) of the accuracy $0.20 \%$ of measured value were applied for the experiments. The Coriolis mass flow meters of the accuracy $0.15 \%$ of measured value were used. COP measurement error was calculated by means of the total derivative approach.

The test rig was equipped with additional loops: the first for the thermal load for the evaporator and the second one for the condenser cooling. These systems allow for adjustment of the refrigerant flow rates as well as for changes of operation parameters in the wide range. The condenser cooling system was equipped with an automatically controlled dry cooler. The thermal load system was equipped with automatically controlled electrical heater. Both systems are fully instrumented with transducers for measurement of temperatures, pressures and flow rates with high accuracy. The rig is equipped with control valves enabling the adjustment of the operation parameters of the motive vapour at the inlet to the motive nozzle of the ejector.

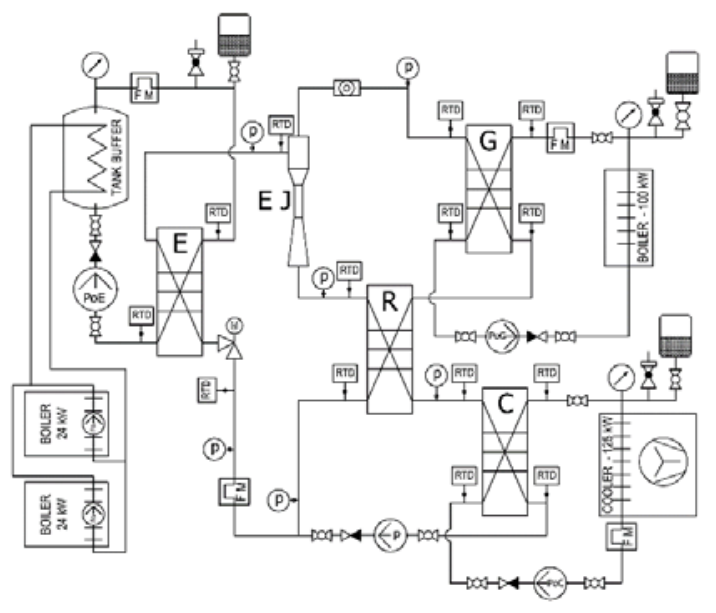

Fig. 2. Schematic of the testing stand: vapour generator (G); condenser $(\mathrm{C})$; evaporator $(\mathrm{E})$; ejector $(\mathrm{EJ})$; refrigerant pump $(\mathrm{P})$; regenerative heat exchanger $(\mathrm{R})$; throttling valve $(\mathrm{M})$; RTD - temperature sensor, $\mathrm{p}$ - pressure transducer, FM - flow meter.

During the experiments the electrical heaters thermal capacity was controlled to maintain the required saturation condition in the vapour generator. The stand is also equipped with control valves enabling the adjustment of the operation parameters of the motive vapour at the inlet to the motive nozzle of the ejector. The diaphragm pump HYDRA-CELL with $3 \mathrm{~kW} / 700$ RPM motor was used as the liquid refrigerant pump.

The ejector was designed and manufactured for the nominal operation conditions assumed as $\mathrm{t}_{\mathrm{g}, \mathrm{sat}}=60^{\circ} \mathrm{C}$, $\mathrm{t}_{\mathrm{e}, \text { sat }}=0^{\circ} \mathrm{C}$. The operation conditions of the first test runs (marked in tables as run No. 1) are very close to the nominal operation conditions, i.e. $t_{\mathrm{g} 1 \text {,sat }}=58^{\circ} \mathrm{C}$, $\mathrm{t}_{\mathrm{e} 1 \text {,sat }}=0^{\circ} \mathrm{C}$. For the second run (run No. 2) the evaporation temperature was increased $\mathrm{t}_{\mathrm{e} 2 \text {,sat }}=6^{\circ} \mathrm{C}$, $\mathrm{t}_{\mathrm{g} 2 \text {,sat }}=58^{\circ} \mathrm{C}$, and the third run (run No. 3) corresponds to the ultra-low motive parameters, i.e. $\mathrm{t}_{\mathrm{g} 33 \text {,sat }}=48^{\circ} \mathrm{C}$ and $\mathrm{t}_{\mathrm{e} 3 \text {,sat }}=7^{\circ} \mathrm{C}$. For all of the runs an average superheating of the motive vapour was $5-6 \mathrm{~K}$, therefore, the motive temperature was lower than $65^{\circ} \mathrm{C}$, and it was even below $55^{\circ} \mathrm{C}$ for run No. 3. Such low motive temperature makes this system unrivalled in the use of low temperature heat sources. 


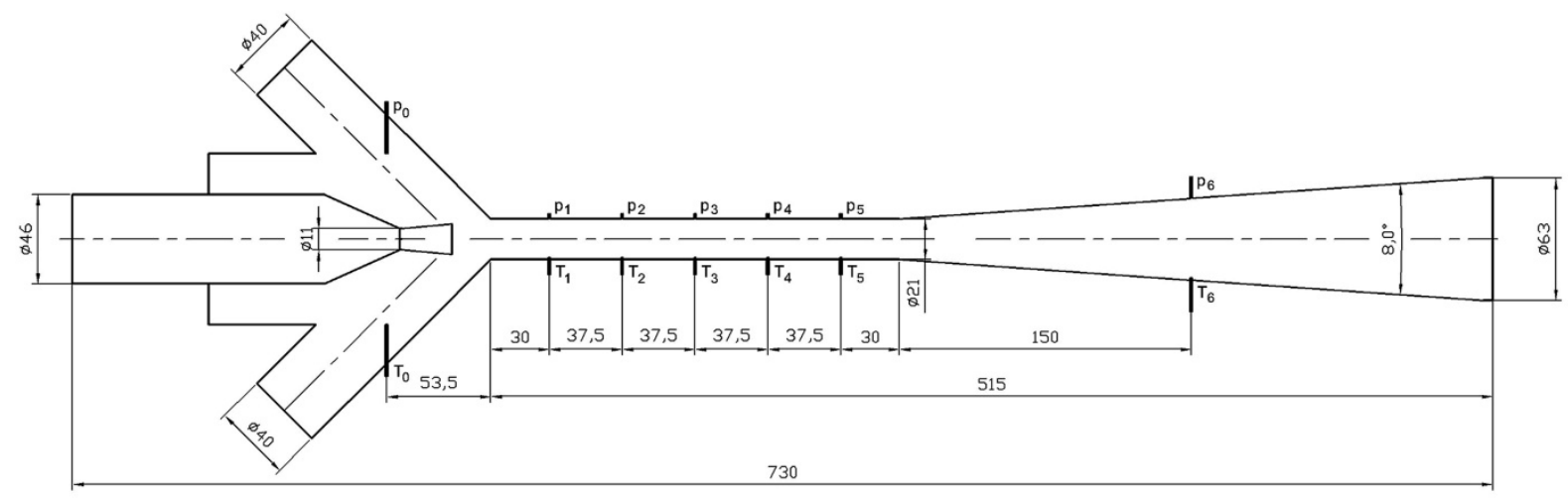

Fig. 3. Schematic of the tested ejector with dimensions in $\mathrm{mm}$.

Under this range of the heat sources the motive temperature the ejection cycles can be considered to be genuinely competitive with absorption and adsorption refrigeration systems. The condensation temperature and corresponding saturation pressure was varied by means of control of the cooling conditions of the condenser, i.e., the mass flow rate of the cooling water was changed for every measurement point. For most the cases of the operation of the refrigeration system the motive source temperature and evaporation temperature are fixed. The condensation temperature is a function of the cooling fluid temperature which can vary in time, and therefore the assumed type of settings of the operation conditions may be thought as adequate for the actual operation of the ejection system.

For the ejector applications, the entrainment ratio is the most important parameter used to describe the ejector performance. Commonly, the entrainment ratio is defined as:

$$
U=\frac{\dot{m}_{e}}{\dot{m}_{g}},
$$

where: $\dot{m}_{g}, \dot{m}_{e}$ are the primary (motive) and the secondary fluid mass flow rates, respectively.

The performance of the ejector system may be also presented by the relationship between the compression ratio versus mass entrainment ratio, $\Pi$. The compression ratio in this paper is thought as ratio of compression produced by ejector, $p_{c}-p_{e}$, and the motive pressure difference $p_{g}-p_{e}$. Therefore, compression ratio is defined as:

$$
\Pi=\frac{p_{c}-p_{e}}{p_{g}-p_{e}}
$$

where $p_{c}$ is condensation pressure, $p_{g}-$ vapour generation pressure, $p_{e}$ - evaporation pressure.

Another parameter describing the ejection system efficiency is the coefficient of performance COP. The $\mathrm{COP}$ is calculated as the ratio of the cooling capacity to the motive energy delivered to the system. In the ejection systems the motive power is the sum of the motive heat and electrical power consumed by the liquid pump Pp:

$$
C O P=\frac{\dot{Q}_{e}}{\dot{Q}_{g}+P_{p}},
$$

where thermal capacities of heat exchangers were calculated as the product of the mass flow rate of refrigerant and the change of the specific enthalpy between the both sides of the heat exchangers:

$$
\begin{aligned}
& \dot{Q}_{e}=\dot{m}_{e}\left(h_{e, o}-h_{e, i}\right), \\
& \dot{Q}_{g}=\dot{m}_{g}\left(h_{g, o}-h_{g, i}\right) .
\end{aligned}
$$

\begin{tabular}{|c|c|c|c|c|c|}
\hline \multicolumn{2}{|c|}{$\begin{array}{l}\text { Generator } \\
\text { saturation } \\
\text { cond. }\end{array}$} & \multicolumn{2}{|c|}{$\begin{array}{c}\text { Evaporator } \\
\text { saturation } \\
\text { cond. }\end{array}$} & \multicolumn{2}{|c|}{$\begin{array}{c}\text { Condenser } \\
\text { saturation cond. }\end{array}$} \\
\hline $\mathrm{p}_{\mathrm{g}, \mathrm{sat}}$ & $t_{\mathrm{g}, \mathrm{sat}}$ & $\mathrm{p}_{\mathrm{e} \text {,sat }}$ & $\mathrm{t}_{\mathrm{e}, \mathrm{sat}}$ & $\mathrm{p}_{\mathrm{c} \text {,sat }}$ & $t_{c, s a t}$ \\
\hline $\mathrm{MPa}$ & ${ }^{\circ} \mathrm{C}$ & $\mathrm{MPa}$ & ${ }^{\circ} \mathrm{C}$ & $\mathrm{MPa}$ & ${ }^{\circ} \mathrm{C}$ \\
\hline \multicolumn{6}{|c|}{ run no. 1} \\
\hline $\begin{array}{c}1.23 \\
\pm 0.02\end{array}$ & $\begin{array}{l}58.3 \\
\pm 0.3\end{array}$ & $\begin{array}{c}0.22 \\
\pm 0.03\end{array}$ & $\begin{array}{c}0.2 \\
\pm 1.0\end{array}$ & $\begin{array}{c}\text { Vary in range } \\
0.416 \text { and } \\
0.600\end{array}$ & $\begin{array}{l}\text { Vary in range } \\
19.2 \text { and } 31.3\end{array}$ \\
\hline \multicolumn{6}{|c|}{ run no. 2} \\
\hline $\begin{array}{l}1.211 \\
\pm 0.03\end{array}$ & $\begin{array}{l}57.8 \\
\pm 0.4\end{array}$ & $\begin{array}{l}0.275 \\
\pm 0.01\end{array}$ & $\begin{array}{c}6.3 \\
\pm 0.8\end{array}$ & $\begin{array}{c}\text { Vary in range } \\
0.430 \text { and } \\
0.569\end{array}$ & $\begin{array}{l}\text { Vary in range } \\
20.2 \text { and } 29.4\end{array}$ \\
\hline \multicolumn{6}{|c|}{ run no. 3} \\
\hline $\begin{array}{l}0.950 \\
\pm 0.04\end{array}$ & $\begin{array}{l}48.0 \\
\pm 1.6\end{array}$ & $\begin{array}{l}0.276 \\
\pm 0.01\end{array}$ & $\begin{array}{c}6.8 \\
\pm 0.9\end{array}$ & $\begin{array}{c}\text { Vary in range } \\
0.425 \text { and } \\
0.490\end{array}$ & $\begin{array}{l}\text { Vary in range } \\
19.8 \text { and } 24.5\end{array}$ \\
\hline
\end{tabular}

Table 1. Operation parameters of the tested ejection refrigeration system.

In this paper the power consumed by the pump was not measured directly, but according to the manufacturer data sheet for the pump, the maximum motor input power is $3 \mathrm{~kW}$. For the purpose of the analysis presented here the power consumed by pump was calculated on the basis of electric current measurement. The average value $I=4.5$ A was taken to calculate the power consumed by mechanical pump. Here, it is:

$$
P_{p}=\sqrt{3} \cdot U \cdot I \cdot \cos \varphi=2.06 \pm 0.15 \mathrm{~kW},
$$

Corresponding author: d.butrymowicz@pb.edu.pl 
where $\cos \varphi=0.66$ was taken from the motor plate.

The last parameter analysed in this paper is the efficiency of the ejector. Relation proposed by Dvorák and Vit [14] was used for this purpose:

$$
\eta=\frac{\dot{m}_{e}}{\dot{m}_{g}} \frac{1-\left(\frac{p_{e}}{p_{c}}\right)^{\frac{\kappa-1}{\kappa}}}{\left(\frac{p_{g}}{p_{c}}\right)^{\frac{\kappa-1}{\kappa}}-1},
$$

where $\kappa$ was calculated from equation of state [15].

Table 2. Operation parameters of the ejector.

\begin{tabular}{|c|c|c|c|c|c|}
\hline \multicolumn{2}{|c|}{$\begin{array}{l}\text { ejector inlet } \\
\text { motive } \\
\text { vapour }\end{array}$} & \multicolumn{2}{|c|}{$\begin{array}{l}\text { ejector inlet } \\
\text { secondary } \\
\text { vapour }\end{array}$} & \multicolumn{2}{|c|}{$\begin{array}{l}\text { ejector outlet } \\
\text { discharge }\end{array}$} \\
\hline$p_{g}$ & $t_{g}$ & $p_{e}$ & $t_{e}$ & $p_{d}$ & $t_{d}$ \\
\hline $\mathrm{MPa}$ & ${ }^{\circ} \mathrm{C}$ & $\mathrm{MPa}$ & ${ }^{\circ} \mathrm{C}$ & $\mathrm{MPa}$ & ${ }^{\circ} \mathrm{C}$ \\
\hline \multicolumn{6}{|c|}{ run no. 1} \\
\hline $\begin{array}{l}1.179 \\
\pm 0.02\end{array}$ & $\begin{array}{l}63.7 \\
\pm 1.2\end{array}$ & $\begin{array}{l}0.218 \\
\pm 0.03\end{array}$ & $\begin{array}{c}8.4 \\
\pm 2.0\end{array}$ & $\begin{array}{l}\text { varied in range } \\
0.420 \text { and } 0.612\end{array}$ & $\begin{array}{l}\text { varied in range } \\
42.6 \text { and } 54.6\end{array}$ \\
\hline \multicolumn{6}{|c|}{ run no. 2} \\
\hline $\begin{array}{l}1.160 \\
\pm 0.02\end{array}$ & $\begin{array}{l}64.7 \\
\pm 1.1\end{array}$ & $\begin{array}{l}0.272 \\
\pm 0.02\end{array}$ & $\begin{array}{l}11.0 \\
\pm 1.5\end{array}$ & $\begin{array}{l}\text { varied in range } \\
0.441 \text { and } 0.579\end{array}$ & $\begin{array}{l}\text { varied in range } \\
30.6 \text { and } 50.8\end{array}$ \\
\hline \multicolumn{6}{|c|}{ run no. 3} \\
\hline $\begin{array}{l}0.950 \\
\pm 0.04\end{array}$ & $\begin{array}{l}54.2 \\
\pm 1.3\end{array}$ & $\begin{array}{l}0.276 \\
\pm 0.01\end{array}$ & $\begin{array}{c}9.6 \pm \\
2.2\end{array}$ & $\begin{array}{l}\text { Varied in range } \\
0.425 \text { and } 0.490\end{array}$ & $\begin{array}{l}\text { varied in range } \\
36.1 \text { and } 43.7\end{array}$ \\
\hline
\end{tabular}

The ejection refrigeration systems generally may be thought as low efficient devices, therefore there is a clear need for further development of simple and low-cost method for improving of COP. The internal heat transfer by means of the internal heat exchanger which is located at the ejector discharge line/ liquid line may be thought as the most simple and effective approach. As it was shown in Fig. 2 the testing stand was equipped with the internal heat exchanger (R) in other to improve COP of the system. The rationality of this solution results among others from the utilisation of superheating of the vapour discharged from the ejector. The vapour superheating at the ejector outlet may be thought as a waste heat so along with condensation heat is transported to the ambient. In the discussed internal heat exchanger heat taken from the superheated vapour is transferred to the liquid feeding the vapour generator. As an effect the temperature of this liquid increases. In effect thermal load required by the vapour generator decreases. Moreover, the cost of application of the additional heat exchanger in the system may be thought as relatively small. Additional advantage of the utilisation of the vapour superheating is related with decrease of the thermal load of the condenser. As an effect the required quantity of the condenser cooling fluid is smaller.
On the basis of the measurement of temperature and pressure of vapour at the heat exchanger inlet and outlet and mass flow rate of vapour, the thermal capacity of the heat exchanger can be found as:

$$
\dot{Q}_{R H X}=\left(\dot{m}_{g}+\dot{m}_{e}\right) \cdot\left(h_{\text {in }}-h_{\text {out }}\right),
$$

where the specific enthalpies are calculated from the equation of state $h=h(t, p)$; the inlet parameters correspond to the ejector discharge, and outlet parameters correspond to the condenser inlet.

Improvement of COP of the system was calculated with assumption that the thermal capacity of the internal heat exchanger $\dot{Q}_{R H X}$ must be added as a motive heat to the system operating without heat exchanger since the liquid that feeds the generator is not preheated. In that case COP of the standard system without the internal heat exchanger is:

$$
C O P_{s t}=\frac{\dot{Q}_{e}}{\dot{Q}_{g}+\dot{Q}_{R H X}+P_{p}}
$$

\section{Results and discussion}

Results of the present investigations are presented in following figures. Operation conditions (based on saturation temperatures) for each line are presented in the figures. As it was mentioned previously several quantities determining the performance of the ejector were investigated. The mass entrainment ratios as a function of condensation temperature for all of the investigated cases are shown in Fig. 4.

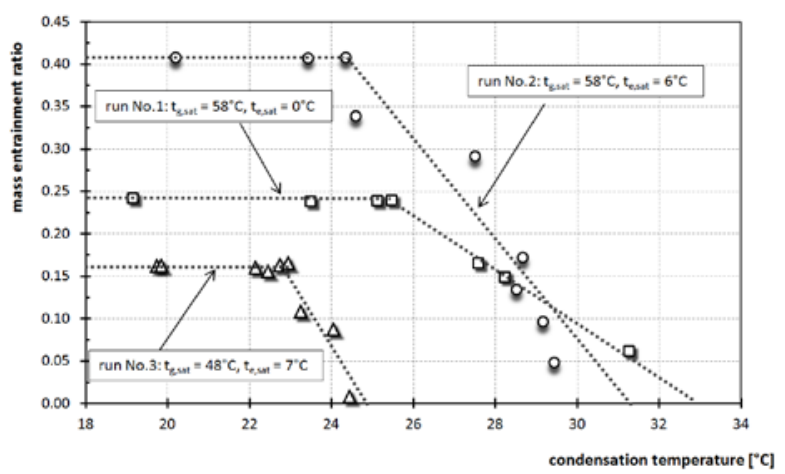

Fig. 4. Relationship between mass entrainment ratio and condensation temperature.

It is seen from this figure that for all runs the ejector operates both at on-design conditions (horizontal part of the performance lines in Fig. 4) and off-design conditions (slope part of the performance lines in Fig.4). For the nominal operation parameters, i.e. $\mathrm{t}_{\mathrm{g} 1}=58^{\circ} \mathrm{C}$, $\mathrm{t}_{\mathrm{e} 1}=0^{\circ} \mathrm{C}$ (run No. 1) the mass entrainment ratio was $\mathrm{U}_{1}$ $=0.24$. Increasing the evaporation temperature up to $6^{\circ} \mathrm{C}$ (Run No. 2) leads to increase of the mass entrainment ratio up to $\mathrm{U}_{2}=0.41$. This effect was expected because of reduction of the pressure difference produced by the ejector. Temperature of the transition point (called as the critical temperature) between the on-design and the offdesign regimes is higher approximately by $1 \mathrm{~K}$ for test 
run No. 1 in comparison with the test run No. 2, i.e. $t_{\mathrm{c} 1 *} \approx$ $25.5^{\circ} \mathrm{C}$, and $\mathrm{t}_{\mathrm{c} 2 *}=24.5^{\circ} \mathrm{C}$. Slope of the approximated operation line of the off-design regime is higher for run No. 2 than for run No. 1. It may be postulated that the wider range of the off-design operation conditions, i.e., the higher condensation temperature range is more desired because the ejector will not stop suddenly when the condensation temperature increases above critical level. The more favourable slope for test run No. 1 gives the higher temperature above which the ejector cannot operate, $t_{c o 1}=33^{\circ} \mathrm{C}$ while for the run No. 2 it is $t_{\mathrm{co} 2}=$ $31{ }^{\circ} \mathrm{C}$.

The measurement points are located along with the approximation line for test run No. 1 when the ejector operates at the off-design conditions, but for run No. 2 the discrepancy of the locations of the measurement points is much higher. It may be therefore concluded that the ejector operates more stable for lower evaporation temperature which correspond to the nominal design operation parameters. As for the case of the ultra-low motive temperature the mass entrainment ratio $\mathrm{U}_{3}=0.16$ was achieved, the transition between operation regimes occurs at temperature $\mathrm{t}_{\mathrm{c} 3^{*}}=23^{\circ} \mathrm{C}$, and the ejector will not operate at condensation temperatures higher than $\mathrm{t}_{\mathrm{co3}}=$ $25^{\circ} \mathrm{C}$. The results clearly show the operation at ondesign and off-design regimes. Operation points are located along the approximation line which proves the stable operation of the ejector under these conditions.

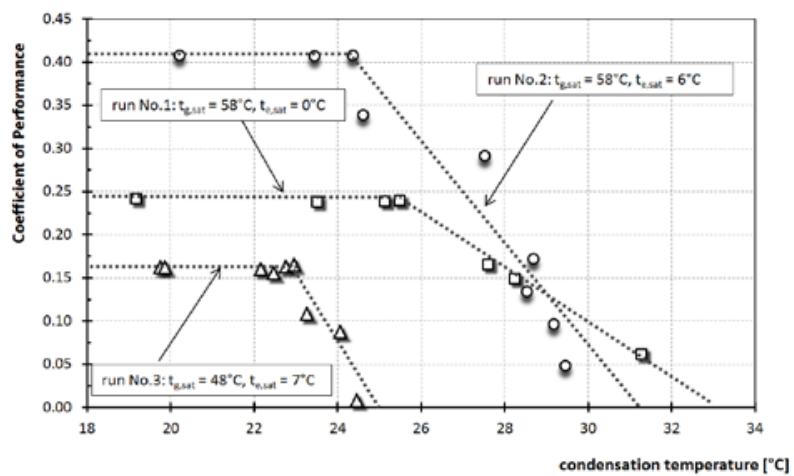

Fig. 5. Relationship between Coefficient of Performance and condensation temperature.

The influence of the condensation temperature on the coefficient of performance COP of the ejection system is presented in Fig. 5. The coefficient of performance is directly related with the mass entrainment ratio and the maximum level of $\mathrm{COP}_{1}=0.24$ was obtained for condensation temperatures below $26^{\circ} \mathrm{C}$. The maximum $\mathrm{COP}_{2}=0.41$ was obtained for higher evaporation temperatures. For run No. 3 when the ejector was driven by the heat source of the lowest temperature $\mathrm{COP}_{3}=$ 0.16 was obtained. The shape and the slope of the performance lines representing COP are the same as shown in Fig. 4.

Performance lines in co-ordinate compression ratio $\Pi$ vs. mass entrainment ratio $U$ are presented in Fig 6.

The shape of the presented lines are typical for the gas ejector. The transition between the on-design and the off-design regimes occurs at $\Pi_{3} \approx 0.26$ for the lowest motive temperature (run No. 3 ), $\Pi_{2} \approx 0.27$ for run No. 2 . The highest compression ratio at the transition point is $\Pi_{1} \approx 0.31$. For runs No. 1 and No. 2 the maximum compression ratio is $\Pi_{1 \max } \approx \Pi_{2 \max } \approx 0.33$ for the lowest mass entrainment ratio. Ejector operation with the lowest motive temperature was able to produce the maximum compression ratio $\Pi_{3 \max } \approx 0.30$.

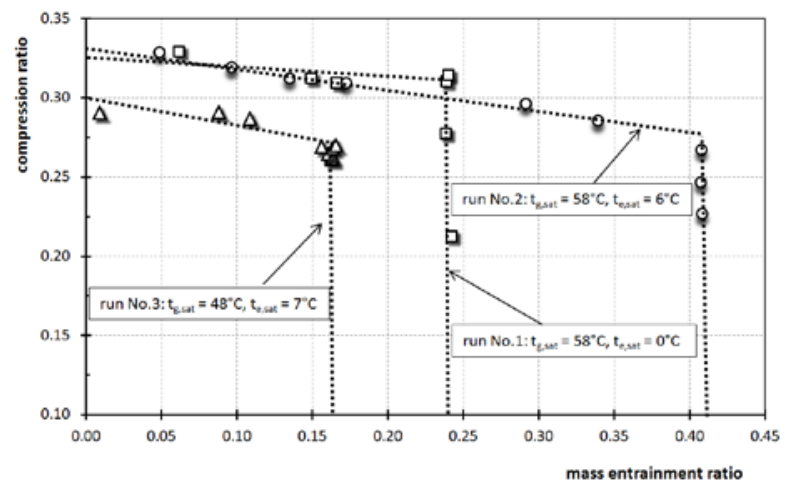

Fig. 6. Relationship between Coefficient of Performance and condensation temperature.

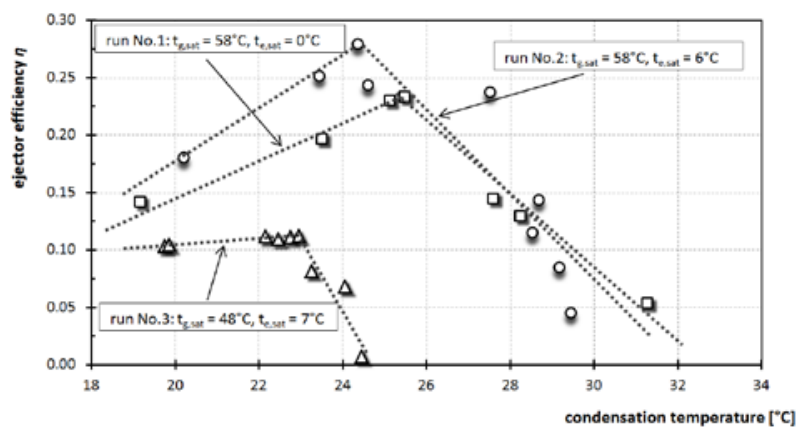

Fig. 7. Efficiency of the tested ejector for various operation conditions.

In Fig. 7 the results of the efficiency of the ejector calculated from eq. (6) are presented. The figures show that the efficiency can be represented by a broken line with maximum point corresponding to the transition point between two operation regimes. For the on-design operation regime, when the mass entrainment ratio is constant, the efficiency increases for lower condensation temperatures as it is seen in Fig. 7. This is due to the increase of ratio of the difference of the specific enthalpies resulting from the increase of the pressure difference between the condenser and the evaporator. When the ejector starts to operate under the off-design condition the ratio of the difference of the specific enthalpies increases, but the mass entrainment ratio decreases. This decrease plays a major role and influences the overall performance of the ejector and as an effect the efficiency decreases.

According to eq. (6), the efficiency increase is related with increasing of the condensation pressure. At the offdesign conditions the efficiency decreases with increasing of the condensation temperature which is a result of the decreasing of the mass entrainment ratio at these operation conditions. For the motive temperature $\mathrm{t}_{\mathrm{g}, \mathrm{sat}}=58^{\circ} \mathrm{C}$ maximum efficiency of the ejector is $\eta_{1 \max }=$ 
0.24 for evaporation temperature $\mathrm{t}_{\mathrm{e}}=0^{\circ} \mathrm{C}$ and $\eta_{2 \max }=$ 0.27 for evaporation temperature $t_{e}=6^{\circ} \mathrm{C}$. Higher ejector efficiency for run No. 2 in comparison with run No. 1 results from the higher mass entrainment ratio $U_{2}>U_{1}$. For the motive temperature $\mathrm{t}_{\mathrm{g} \text {,sat }}=48^{\circ} \mathrm{C}$ the maximum efficiency of the ejector is slightly above $\eta_{3 \max }=0.10$.

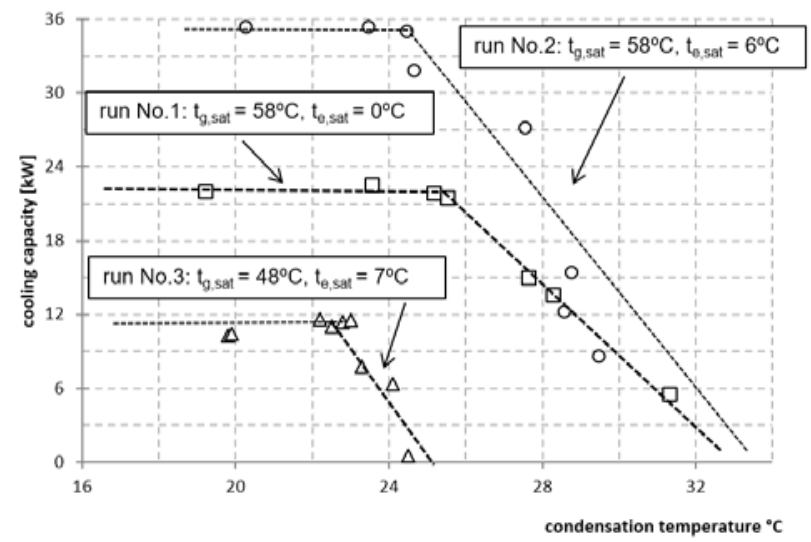

Fig. 8. Cooling capacity of the system versus condensation temperature.

Cooling capacity of the evaporator for the on-design operation regime was $22 \mathrm{~kW}$ for run No. 1, and $35 \mathrm{~kW}$ for run No. 2. For run No. 3 the evaporator cooling capacity almost $11 \mathrm{~kW}$ was observed. When the system operates at the off-design regime the cooling capacity decreases for all three runs, as expected.

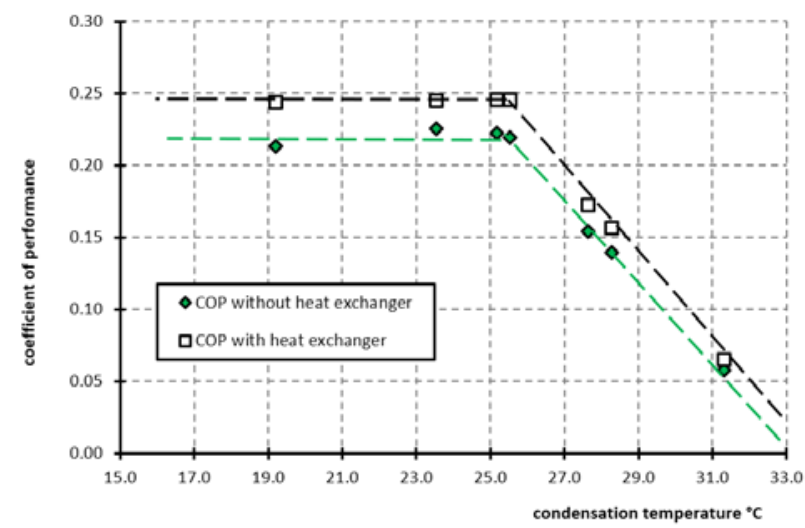

Fig. 9. Coefficient of performance of the system operating with and without regenerative heat exchanger for run No.1.

The results presented in Fig. 9 to Fig. 11 show that application of internal heat exchanger improves COP of the system. It is seen in Fig. 9 that when system operates at the evaporation temperature $t_{e}=0^{\circ} \mathrm{C}$ the improvement of COP is more stable at off-design regime in comparison with the second test run at which $\mathrm{t}_{\mathrm{e}}=6^{\circ} \mathrm{C}$ (Fig. 10). For all test runs the improvement of the COP within the range $10-12 \%$ was achieved which can be thought as a very attractive.

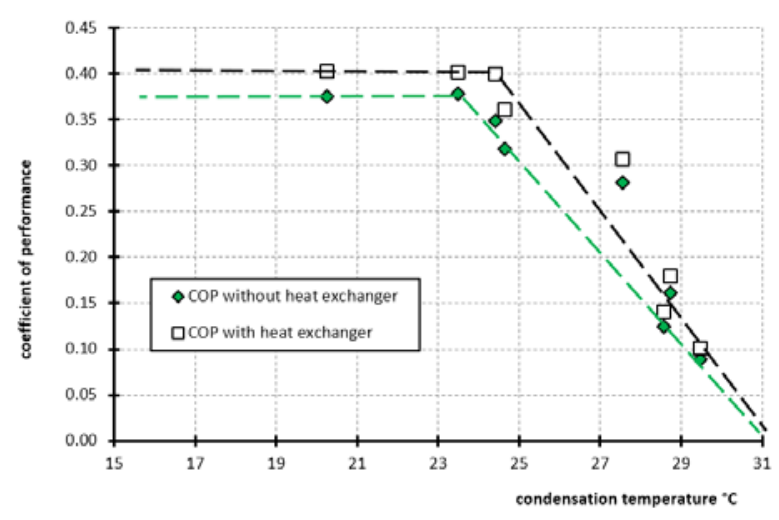

Fig. 10. Coefficient of performance of the system operating with and without regenerative heat exchanger for run No.2.

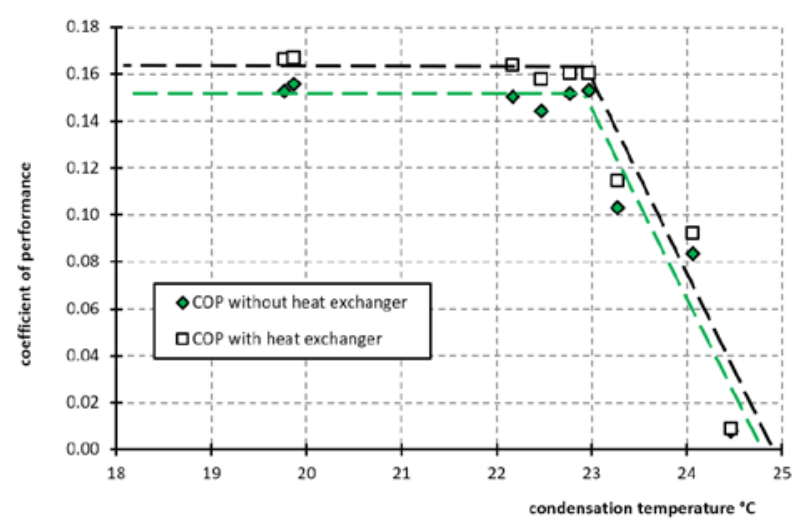

Fig. 11. Coefficient of performance of the system operating with and without regenerative heat exchanger for run No.3.

\section{Conclusions}

On the basis of presented results following conclusions can be drawn:

- Application of refrigerant R-1234ze(E) provides the typical performance of ejection refrigeration systems.

- Ejector cycle with low GWP refrigerant R-1234ze(E) is able of effective operation when low temperature heat source (lower than $\mathrm{t}_{\mathrm{g} \text {,sat }}=60^{\circ} \mathrm{C}$ or even below $\mathrm{t}_{\mathrm{g} \text {,sat }}=$ $50^{\circ} \mathrm{C}$ ) is used.

- The tested ejector achieved the maximum efficiency at level 0.27 , but for most of the operation points the range $0.10 \div 0.25$ was obtained. These values can be thought as rational taking into consideration low level of the motive source temperature.

- The internal heat exchanger for COP improvement was applied for this fluid in the ejection refrigeration system. The superheating of vapour at the ejector outlet was applied to increase the system efficiency for approximately $10-12 \%$.

This research was carried out as part of work no. S/WM/1/2018 and financed from funds for education of the Ministry of Science and Higher Education. 


\section{References}

1. International Energy Agency, The Future of Cooling: Opportunities for energy efficient air conditioning, Report OECD/IEA, 2018

2. M. Calero, E. Alameda-Hernandez, M. FernándezSerrano, A. Ronda, M.A. Martín-Lara Energy consumption reduction proposals for thermal systems in residential buildings, Energy \& Buildings 175 (2018) 121-130

3. Regulation (EU) No 517/2014 of the European Parliament and of the Council on fluorinated greenhouse gases and repealing Regulation (EC) No $842 / 2006$

4. K. Śmierciew, D. Butrymowicz, J. Gagan, Assesment of Refrigerant Selection for Ejection System Driven by Low-Grade Heat, 2016 Purdue Compressor Engineering, Refrigeration and Air Conditioning and High-Performance Buildings Conferences, Purdue, USA, 2016, ID 2667.

5. A. Arbel, M. Sokolov, Revisiting solar-powered ejector air conditioner - the greener the better, Solar Energy 77 (2004) 57-66.

6. J. M. Abdulateef, et. Al, Review of Solar-Driven Ejector Refrigeration Technologies, Renewable and Sustainable Energy Reviews 13 (2009) 1338-1349.

7. H.K Ersoy, S. Yalcin, R. Yapici, M. Ozgoren, Performance of a solar ejector cooling-system in the southern region of Turkey, Applied Energy 84 (2007) 971-983.

8. A. Selvaraju, A. Mani, Analysis of an ejector with environment friendly refrigerants, Applied Thermal Engineering 24 (2004), 827- 838

9. J., Chen, S. Jarall, H. Havtun, B. Palm, 2015, A review on versatile ejector applications in refrigeration systems, Renewable and Sustainable Energy Reviews 49, 67-90.
10. G. Besagni, R. Mereu, F. Inzoli, 2016, Ejector refrigeration: A comprehensive review, Renewable and Sustainable Energy Reviews 53, 373-407

11. S. Elbel, N. Lawrence, 2016, Review of recent developments in advanced ejector technology, International Journal of Refrigeration 62, 1 - 18.

12. D. Butrymowicz, K. Śmierciew, J. Karwacki, J. Gagan, 2014, Experimental investigations of lowtemperature driven ejection refrigeration cycle operating with isobutane, International Journal of Refrigeration 39, 196-209.

13. K. Smierciew, J. Gagan, D. Butrymowicz, J. Karwacki, 2014, Experimental investigations of solar driven ejector air-conditioning system, Energy and Buildings 80, 260-267.

14. V. Dvořák, T. Vit, 2005. Experimental and numerical study of constant area mixing. In: 16th Int. Symp. on Transport Phenomena, Prague.

15. E.W. Lemmon, M.L. Huber, M.O. McLinden, NIST Standard Reference Database 23: Reference Fluid Thermodynamic and Transport PropertiesREFPROP, Version 9.1, National Institute of Standards and Technology, Standard Reference Data Program, Gaithersburg, 2013. 